\title{
Multidecadal oscillatory behaviour of rainfall extremes in Europe
}

\author{
Patrick Willems
}

Received: 28 November 2012 / Accepted: 28 June 2013 /Published online: 30 July 2013

(C) The Author(s) 2013. This article is published with open access at Springerlink.com

\begin{abstract}
Many studies have observed changes in the frequency and intensity of precipitation extremes and floods during the last decade(s). Natural variability by climate oscillations partly determines the observed evolution of precipitation extremes. Based on a technique for the identification and analysis of changes in extremes, this paper shows that precipitation extremes have oscillatory behaviour at multidecadal time scales. The analysis is based on a unique dataset of 108 years of 10-minute precipitation intensities at Uccle (Brussels), not affected by instrumental changes. We also checked the consistency of the findings with long precipitation records at 724 stations across Europe and the Middle East. The past 100 years show for northwestern Europe, both in winter and summer, larger and more precipitation extremes around the 1910s, 19501960s, and more recently during the 1990s-2000s. The oscillations for southwestern Europe are anti-correlated with these of northwestern Europe, thus with oscillation highs in the 1930-1940s and 1970s. The precipitation oscillation peaks are explained by persistence in atmospheric circulation patterns over the North Atlantic during periods of 10 to 15 years.
\end{abstract}

\section{Introduction}

Recent trends have become clear in global and regional datasets of atmospheric and oceanographic variables, e.g., for atmospheric and sea surface temperatures and pressures (Stott 2003; Gillett et al. 2003; Jones et al. 2003). Trends in precipitation series are less clear (Lambert et al. 2004; Zhang et al. 2007; Wentz et al. 2007; Kundzewicz 2012), certainly for extreme precipitation conditions at both small and large time scales, which are the key drivers of floods along rivers and urban drainage systems. Based on historical precipitation records, it is difficult to test the significance of the recent trends because only the limited data series from the past one or two centuries have good accuracy (Zhang et al. 2007) and because of the strong natural variability (the high noise-signal ratio). Next to the sporadic annual fluctuations, the global climate system shows temporal and spatial oscillations with modes of variability at decadal to

Electronic supplementary material The online version of this article (doi:10.1007/s10584-013-0837-x) contains supplementary material, which is available to authorized users.

P. Willems $(\bowtie)$

Hydraulics Division, KU Leuven, Kasteelpark Arenberg 40, 3001 Leuven, Belgium

e-mail: Patrick.Willems@bwk.kuleuven.be

URL: http://www.kuleuven.be/cv/u0009249e.htm 
multidecadal time scales. The multidecadal oscillations have been reported by several authors based on series of global surface air temperature (Folland et al. 1984; Schlesinger and Ramankutty 1994), paleo-climate data from ice and sediment cores, corals and tree rings (Mann et al. 1995; Fischer and Mieding 2005), sea level pressure (SLP), surface air pressure (SAP) and atmospheric circulation (Goldenberg et al. 2001), sea surface temperature (SST) (Grosfeld et al. 2007; Kerr 2000; Delworth and Mann 2000) and annual precipitation depths (Faure and Gac 1981). The patterns for precipitation extremes, however, have not been studied to the same detail, or results were so far less clear (Enfield et al. 2001).

In Ntegeka and Willems (2008), we analyzed these patterns (both the recent trends and the multidecadal oscillations) in a unique 10-minute series of precipitation intensities, recorded by the Royal Meteorological Institute of Belgium at Uccle (Brussels), since 1898. This was done by means of a technique identifying anomalies in extreme quantiles. The same method is applied in this paper for further investigation on these oscillations, for checking the consistency with other long-term series of precipitation in Europe, with other climate and ocean datasets and with indicators of large scale atmospheric circulation in the North Atlantic region.

\section{Methods}

\subsection{Analysis of extreme anomalies}

The anomalies in extremes are based on independent extremes extracted from the historical series. After ranking, these extremes correspond to quantiles (extremes for given empirical probabilities of being exceeded or for given mean recurrence intervals). The empirical probabilities or mean recurrence intervals are computed based on all extremes extracted from for the full available series and based on subsets of extremes in subperiods of 5 to 15 years length. Quantiles in a subperiod are compared with the corresponding quantiles derived from the full series. The relative difference between the subperiod based quantile and the corresponding full period based quantile is computed for all quantiles above a specific threshold. This threshold (above which the values are considered "extreme") corresponds to a specific frequency of occurrence in time or a specific mean recurrence interval. For this study, subperiods of 5 to 15 years have been considered and the analysis was made based on the four climatological seasons. For time scales higher than the time step of the series, the anomalies are calculated from the aggregated series. For instance for the Uccle series of 10minute precipitation intensities, aggregation times considered were $10 \mathrm{~min}, 1 \mathrm{~h}, 1$ day, 1 week and 1 month (using a moving average procedure with a moving step of $10 \mathrm{~min}$ ). Because changes in extreme precipitation quantiles might be explained by both changes in the number of extreme precipitation events and changes in the precipitation intensity per event, anomalies were derived for each of these variables.

More specifically, from a series with given time step (e.g. $10 \mathrm{~min}$, monthly) and length of $L$ years, extremes are extracted using independence criteria. These define that precipitation extremes are independent, or approximately independent, when they are separated by a time span of at least $12 \mathrm{~h}$ for aggregation times of $12 \mathrm{~h}$ or lower. For aggregation times higher than $12 \mathrm{~h}$, independent extremes are separated by a time span equal to or greater than the aggregation time. The ranked extremes represent quantiles $x(L / i)$ with empirical recurrence intervals $L / i$, where $i$ is the rank number ( 1 for the highest). The full series thereafter is divided in subperiods with fixed length $L_{b}$, moving from the first to the last subperiod with a moving step of 1 year. When the quantiles present in each subperiod are denoted $x_{b}\left(L_{b} / i_{b}\right)$, where $i_{b}$ is the rank number ( 1 for the highest in the subperiod), the anomaly percentage of 
each of these quantiles is calculated by $100 *\left(x_{b}\left(L_{b} / i_{b}\right) / x\left(L_{b} / i_{b}\right)-1\right)$. When $L_{b} / i_{b}$ does not match one of the $L / i$ recurrence intervals, the closest $L / i$ is considered. The anomaly percentages for all empirical recurrence intervals above the considered threshold are then averaged to obtain the mean anomaly per subperiod. It is plotted at the central time moment of the subperiod. Results are hereafter shown for subperiods sliding with a 1 year step, hence representing the temporal variability in extreme quantile anomalies. An anomaly of $10 \%$ plotted for a given year means that extreme quantiles in the subperiod centred on this year are on average $10 \%$ higher in comparison with the quantiles derived from the full available series (anomaly 0 ). By analyzing the subperiods, (multi)decadal variability is isolated from higher frequency fluctuations such as interannual variability.

\subsection{Test of significance}

To test the significance of the anomalies in extreme quantiles, $95 \%$ confidence intervals on the anomaly percentages are calculated under the hypothesis of randomness (no trend, no serial dependence or persistence) of the extremes. When the empirical anomalies go beyond these confidence intervals, the non-persistence hypothesis can be rejected. The $95 \%$ confidence intervals are calculated as follows. An empirical or theoretical distribution is derived for the extremes extracted from the full historical series. From this extreme value distribution, 1,000 random samples (of same size as the historical extremes) are generated. For each random sample, the anomaly calculation is repeated, leading to 1,000 anomaly values for each year of the historical series. After ranking of the 1,000 values, the 25 th and 975th sample values define the $95 \%$ confidence intervals for each particular year.

For the Uccle precipitation series, a two-component exponential distribution is applied as extreme value distribution. This is done following the method proposed and evaluated in Willems (2000) and Willems (2013). Results of the significance testing based on that theoretical distribution versus resampling to derive confidence intervals based on the empirical frequency distribution did not show much difference in the identification of significant anomalies. For that reason, empirical frequency distributions were applied for the other data series considered in this study.

\section{Results}

\subsection{Multidecadal oscillations in precipitation extremes}

Figures 1 and 2 show the anomalies in extreme precipitation quantiles based on the unique 10-minute series of 108-years precipitation intensities since 1898. Same instrument recorded the series during the entire period and the series was thoroughly quality checked (Demarée 2003). The series thus is not affected by measurement inhomogeneities due to instrumental differences. The relevant time scales considered in the analysis are the ones that explain floods along rivers and in urban drainage systems. They correspond with the systems' response time to precipitation, and range from hours to months for rivers, and from $10 \mathrm{~min}$ to a few hours for urban drainage systems (Chow et al. 1988).

Oscillations are observed in the Uccle series with higher extreme precipitation quantiles in periods around the 1910s, 1950-1960s and recently during the past 20 years (Fig. 1). This clustering of extremes is similar for both the winter and summer seasons. Lower extreme precipitation quantiles are observed in the 1930-1940s and the 1970s. During the past century, multidecadal oscillation highs occurred with periods of 35 to 45 years (Fig. 1). A 


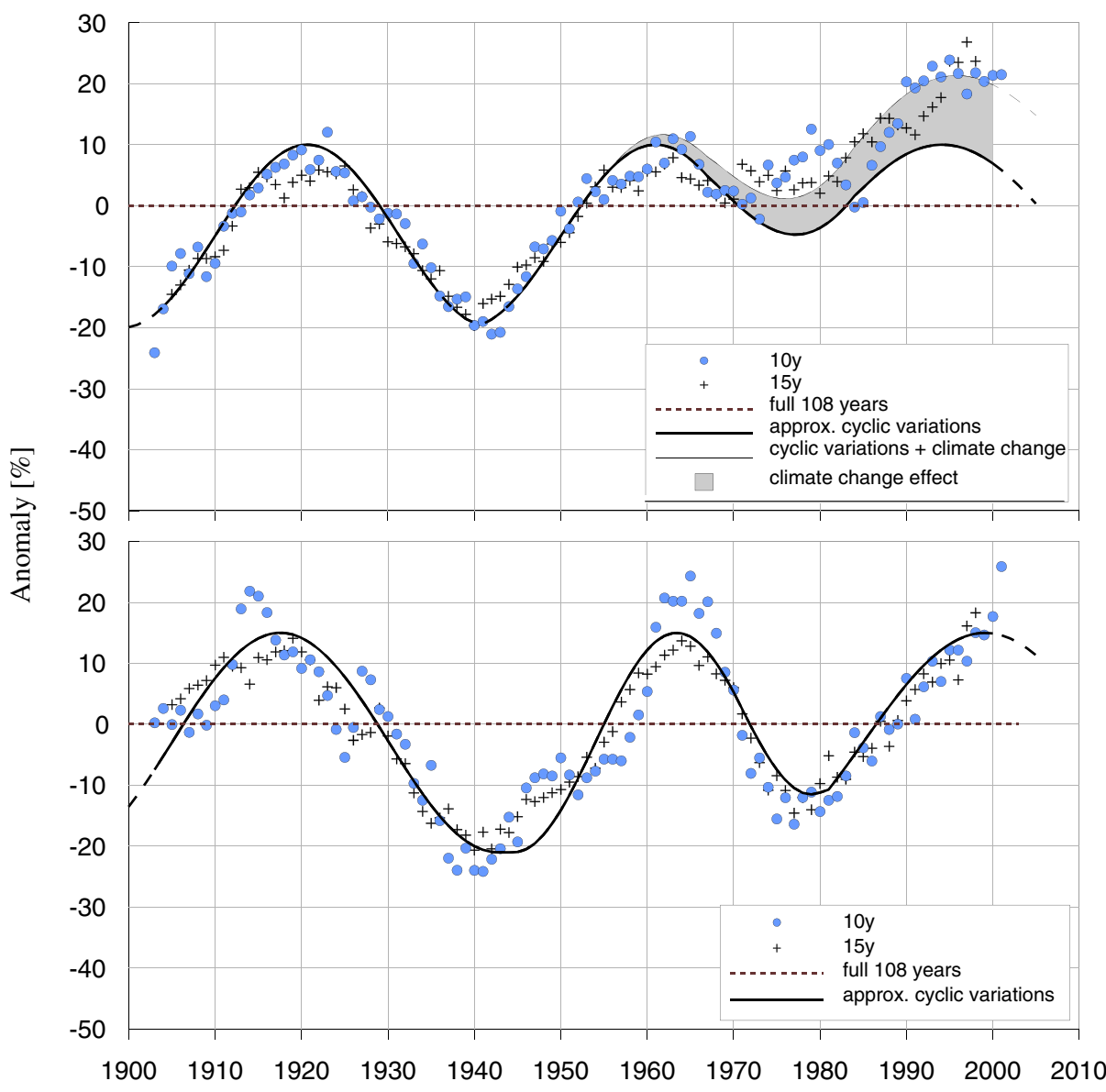

Fig. 1 Quasi-cyclic approximations with periods of 40 and 35 years length to the multidecadal oscillations in the extreme quantiles of 10-minute precipitation depths (relative to the ones based on the full 108 years from 1898), for 10 and 15-years subperiods and intensities $>0.8 \mathrm{~mm}$ in DJF (top figure) and $>1 \mathrm{~mm}$ in JJA (bottom figure)

period with only 3 cycles is too short to draw statistically strong conclusions on this property, but results clearly indicate the presence of long-term temporal persistence in the precipitation extremes, with a cluster of precipitation extremes during the past 20 years. For the summer period (JJA: June-July-August), highest extreme precipitation quantiles are observed in the 1960 s, slightly higher than the more recent ones from the past 20 years. These results suggest that the recent cluster of heavy rain storms is caused by hydrometeorologic conditions which are less or equally extreme than what was observed during the 1960s. Of course, in the mean time, land use strongly changed (e.g. urban areas expanded and sewerage systems were built at a large scale) such that hydrological effects nowadays strongly differ from the ones in the 1960s.

For the winter period (DJF: December-January-February), observations are different. 10 minute extreme precipitation quantiles during the past 20 years are about $25 \%$ higher in 


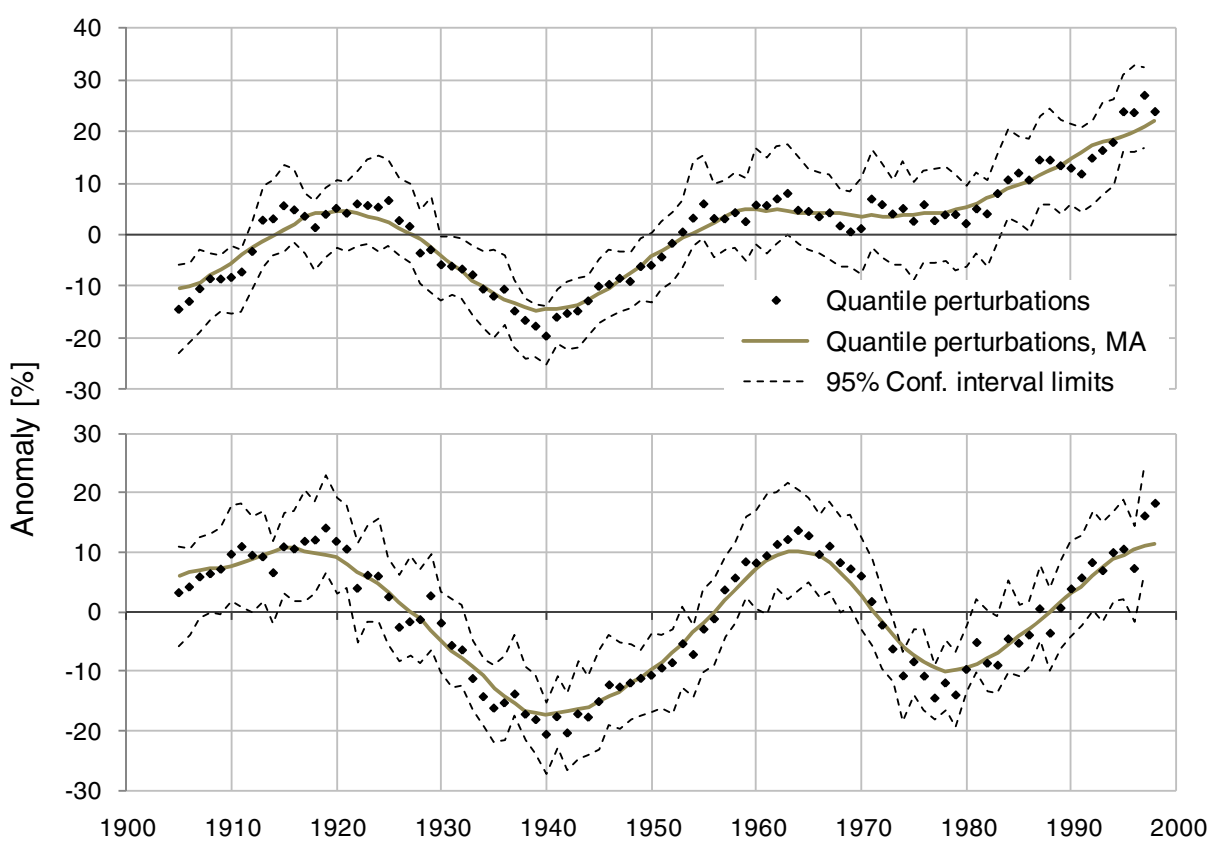

Fig. 2 Anomalies in extreme quantiles of 10-minute precipitation depths (relative to the ones based on the full 108 years from 1898), $95 \%$ confidence intervals and 10-years moving average (MA) filter, for 15-years subperiods, and intensities $>0.8 \mathrm{~mm}$ in DJF (top figure) and $>1 \mathrm{~mm}$ in JJA (bottom figure)

comparison with the ones based on the full 108 years (Fig. 1), which is about $15 \%$ higher than during previous cluster periods of the past century. This increase might be attributed to anthropogenic climate change, given that the change is in sign and order of magnitude consistent with the global warming impact predictions by regional climate models (Christensen and Christensen 2003; Lenderink et al. 2007; Min et al. 2011; Willems et al. 2012; IPCC 2007, 2012); see Baguis et al. (2009), Willems and Vrac (2011) and Willems (2013) for the particular impact results on precipitation extremes at Uccle. The analysis of this attribution is, however, beyond the scope of this article.

The high positive anomalies in extreme precipitation quantiles in the 1910s, 1950-1960s and $1990 \mathrm{~s}-2000 \mathrm{~s}$ and the low negative anomalies in the 1930s-1940s and 1970s are significant at the $5 \%$ significance level (Fig. 2). The anomalies encompass aspects of frequency (number of extremes) and amplitude (intensity) of the extremes. Results therefore were also separately analyzed for the mean precipitation intensity per extreme precipitation event and for the number of extreme precipitation events per subperiod (see Supplementary Information). It was found from that analysis that the temporal variability in mean intensity and in event frequency have similar patterns although the variability in the number of extremes explains larger part of the variability in the quantile anomaly. Similar observations were made by Gregersen et al. (2013) for hourly precipitation in Denmark, albeit for shorter series of 10-31 years length.

The procedure for calculation of the anomalies in extreme precipitation quantiles has been repeated for subperiods of 5,10 and 15 years, for aggregation times of $10 \mathrm{~min}, 1$ day and 1 month, and separately for summer (JJA) and winter (DJF) periods. Conclusions are consistent for all these subperiods, aggregation times and seasons (see Supplementary Information). Also 
when the mean recurrence interval, above which the values are considered extreme, is varied, conclusions remain consistent (see Supplementary Information).

\subsection{Similar multidecadal oscillations in other climate and ocean datasets}

The multidecadal oscillations identified for the Uccle precipitation series were compared with the results of similar analysis for the extreme quantiles of daily and monthly precipitation, temperature and cloud cover in central-western Europe (see Supplementary Information), some of longer length than the Uccle precipitation series. They indicate that multidecadal oscillations with irregular periodicities in the range 30-60 years were present also in previous centuries. Oscillations with periods of 50 to 100 years (Delworth and Mann 2000; Enfield et al. 2001; Grosfeld et al. 2007) were also observed before, but for SST and SLP reconstructions in the North Atlantic. Based on paleoclimate data, these oscillations seem to hold for the last millennium (Grosfeld et al. 2007). Based on temperature reconstructions for France since 1370 (Yiou and Masson-Delmotte 2005), multidecadal oscillation peaks appear at similar periods as the ones derived here for Uccle. The oscillations in precipitation extremes are reflected in river discharge series, as is shown in the example of the Meuse river in Fig. 3.

The analysis also has been repeated for daily precipitation series of 724 other meteorological stations in Europe and the Middle East. They were obtained from the ECA\&D database (Klein Tank et al. 2002), and have lengths of 40 years or more in common with the Uccle precipitation series. The series have undergone routine quality control procedures by the supplying institutes (Klein Tank et al. 2002). Of the 724 stations, 26 stations had all years of the full available Uccle precipitation series in common, 55 stations more than 90 years, 134 stations more than 60 years. When spatial correlations are calculated between the anomalies in extreme daily precipitation between Uccle and all ECA\&D precipitation series, positive correlations are found with stations in central-western Europe, and anti-correlations with stations in southwestern and northern Europe (Fig. 4). The Supplementary Information shows based on a t-test that most significant correlations are found for stations with positive correlations close to Uccle.

Examples of comparisons of the anomalies in daily precipitation extremes between Uccle and other stations in Europe are given in Fig. 5. These examples can be seen as "typical" for

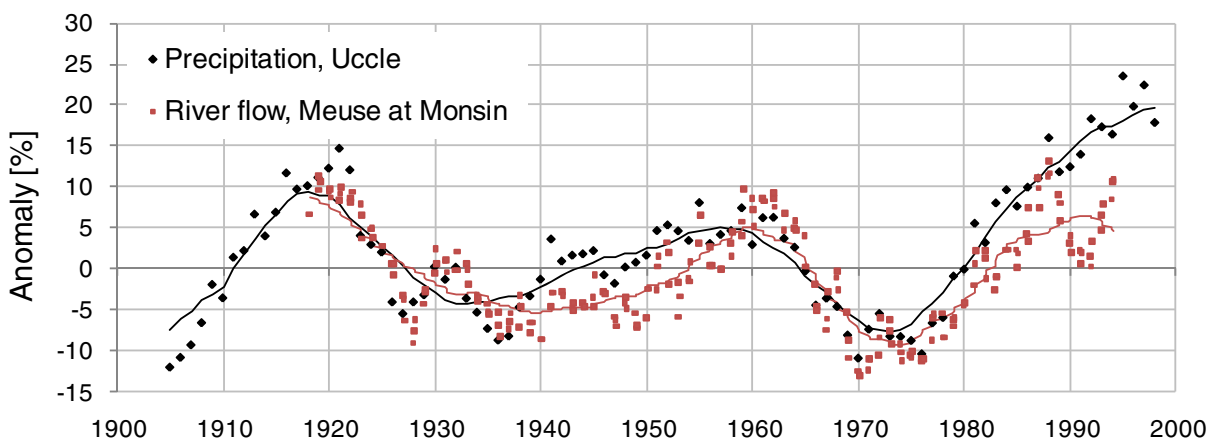

Fig. 3 Anomalies in quantiles of monthly precipitation at Uccle and monthly river flows for the Meuse river at Monsin (source data: Rijkswaterstaat, The Netherlands; Ashagrie et al. 2006), for 15-years subperiods and all months in DJF 


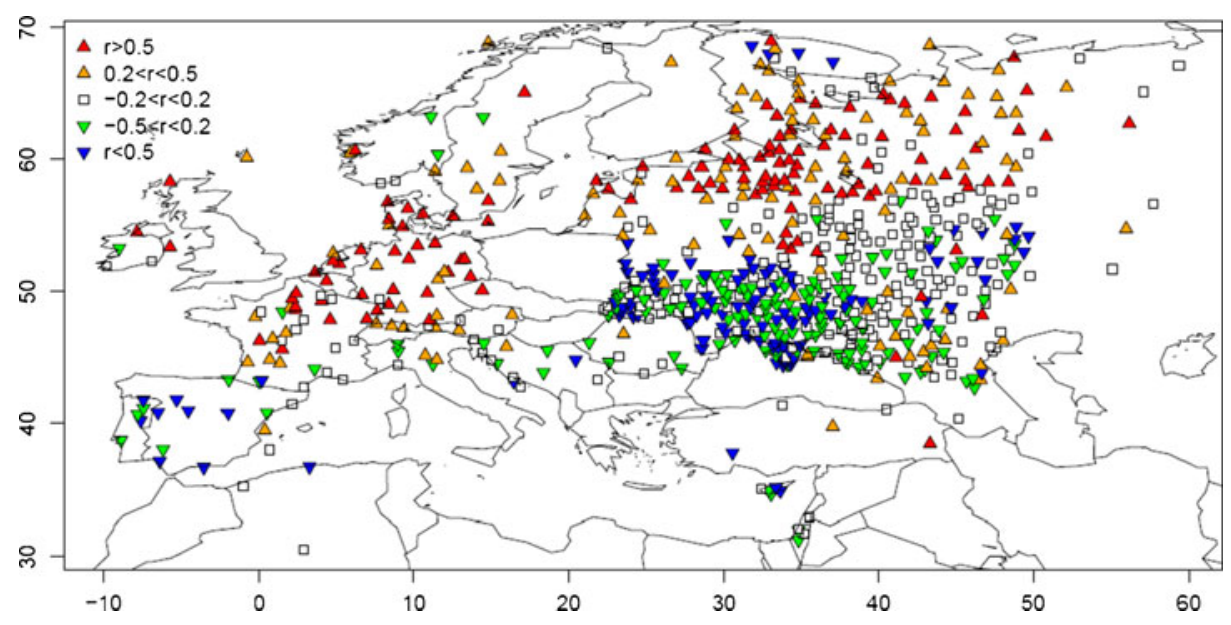

Fig. 4 Correlation coefficients (r) of the anomalies in extreme quantiles of daily precipitation between Uccle and other stations of the ECA\&D database with at least 40 years of data in common, for 15-years subperiods and 15 most extreme days p.a. in DJF

different regions of western Europe. Results indicate that stations in central-western regions close to Belgium have strong positive correlations in multidecadal oscillations of extreme precipitation quantiles. Also stations located in the north of The Netherlands, Denmark and the south of Norway show positive correlations but with stronger increasing trends during most recent years. In central France and Switzerland, the oscillation peaks are shifted to earlier years. For southwestern Europe, the time shifts are stronger, leading to anticorrelations in the multidecadal extreme precipitation oscillations. Another illustration of this anticorrelation is provided in Fig. 6, which compares monthly precipitation extremes between Uccle and Bologna. The anti-correlation can be explained by spatial dependencies of the atmospheric regimes (see section 4). The precipitation oscillation lows for Uccle and precipitation oscillation highs for Bologna, for instance, match with periods with more days of blocking regime over Scandinavia.

\section{Discussion: links with large-scale circulation}

Several studies identified links between the North Atlantic climate, atmospheric circulation or SLP/SAP patterns, the North Atlantic Oscillation (NAO) index (Hurrell 1995; Jones et al. 1997) and the North Atlantic SST, as reflected by the AMO (Atlantic Multidecadal Oscillation) index (Mann et al. 1995; Goldenberg et al. 2001). We therefore applied our quantile perturbation analysis technique also to SLP series across Europe and the North Atlantic, and to the number of days with given weather regimes (available for the UK, following the Lamb's daily synoptic index; Lamb 1972; Hulme and Barrow 1997) and to the AMO index (Fig. 7). It is found that the oscillation highs in the 1910s, 1950-1960s and 1990s-2000s coincide for winter (DJF) with positive SLP anomalies between the Azores and Scandinavia. The precipitation oscillation highs thus are explained by an increase in the frequency of westerly circulation (more maritime climate). Oscillation lows of the 1930s1940s and 1970s coincide with periods where atmospheric blocking over Scandinavia occurs more frequently. Links with the NAO index appear less strong: the 1910s and 1990s oscillation 

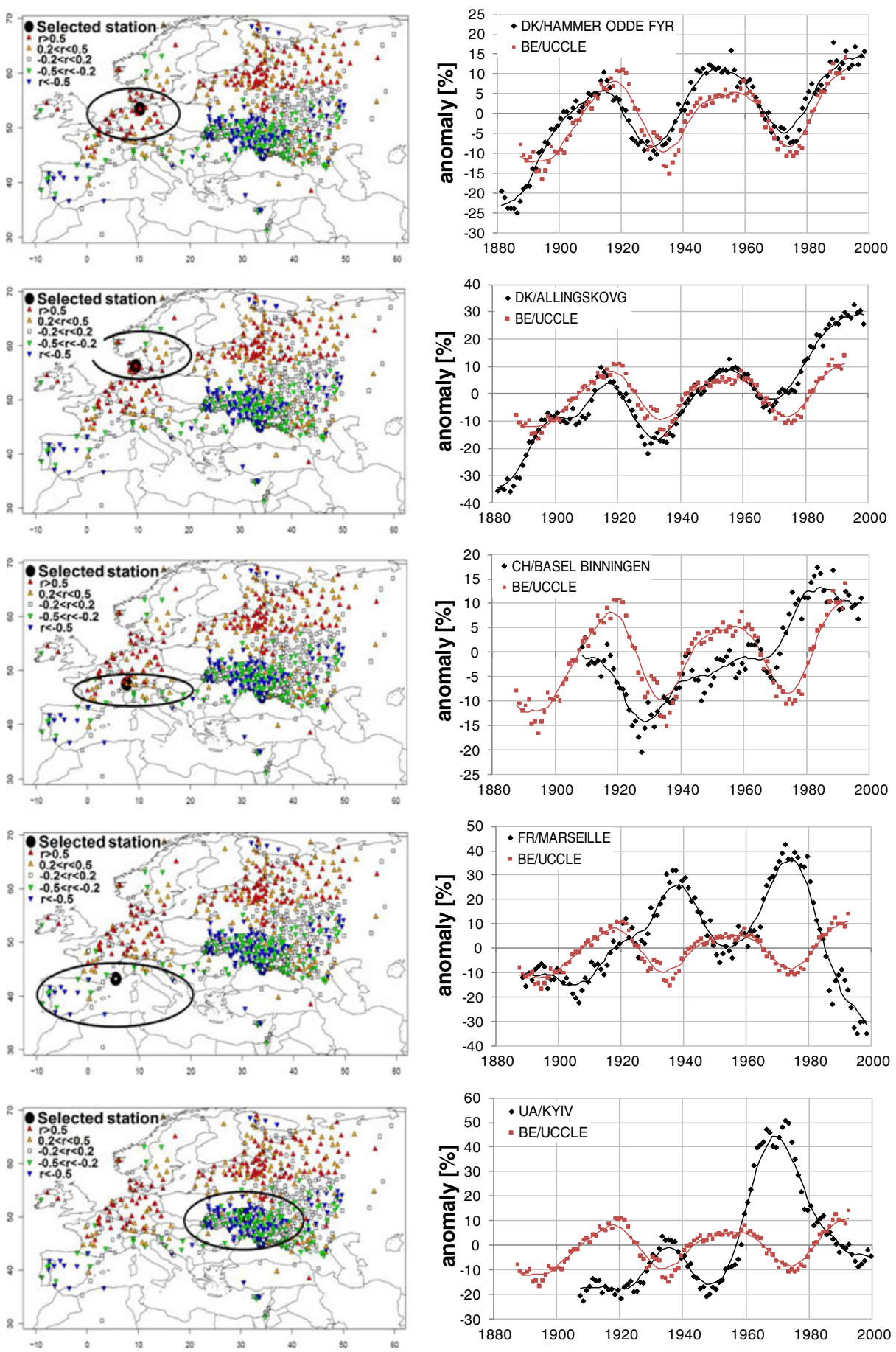
4 Fig. 5 Typical examples of comparisons of the anomalies in extreme quantiles of daily precipitation between Uccle and selected stations of the ECA\&D database in different regions of western Europe, for 15-years subperiods and 15 most extreme days p.a. in DJF

highs correspond with positive phases of the NAO index, but the 1950-1960s oscillation high does not coincide with such phase.

When a modified index is introduced based on SLP differences between the Azores and Scandinavia, the multidecadal oscillations in this index appear more similar than is the case for the NAO index (Fig. 7). The modified index is hereafter called Azores-Scandinavia Oscillation (ASO) index and is calculated in two versions based on the SLP differences between Gibraltar and Haparanda (Sweden), or between Gibraltar and Vestervig (Denmark). The correlation coefficient between the monthly quantile anomalies based on the NAO index and the monthly precipitation quantile anomalies at Uccle, shown in Fig. 7, equals 0.12. This coefficient increases to 0.30 when the NAO index is replaced by the ASO index based on Vestervig. It further increases to 0.52 when a phase shift of 6-7 years is applied. The $t$-test shows that the one-sided $p$-value for a zero correlation hypothesis is $11.6 \%$ in the latter case.

The north-south pressure-based dipole anomaly between the Azores and Scandinavia, as reflected by the ASO index, is indeed strongly related with the direction and strength of the geostrophic wind over the eastern North Atlantic and northwestern Europe (zonal circulation) (Grosfeld et al. 2007; Luterbacher et al. 2004; Deser and Blackmon 1993; Yiou and MassonDelmotte 2005). During positive phases of the ASO, enhanced cyclonic flow over Scandinavia brings warm and wet oceanic air over northwestern Europe (the so-called westerlies). This is also reflected in the temporal increase of the AMO index in these periods (Fig. 7). During negative phases of the ASO, wet air is brought over southwestern Europe, while the climate is dry over north- and central-western Europe. These negative phases of the ASO correspond with high SLP anomalies over Scandinavia (Scandinavian blocking regime). Yiou and Nogaj (2004) have shown earlier that this blocking regime over Scandinavia is correlated with dry winter episodes in northwestern Europe and wet episodes in southern Europe. This is for the DJF season confirmed in Fig. 7. For summer (JJA), precipitation extremes are less explained by this SLP dipole anomaly (the ASO index) but by the occurrence of cyclonic weather and low SLP above Belgium - The Netherlands - UK - northern France and high SLP above southern Europe (not shown). Also this is confirmed when the multidecadal oscillations are studied.

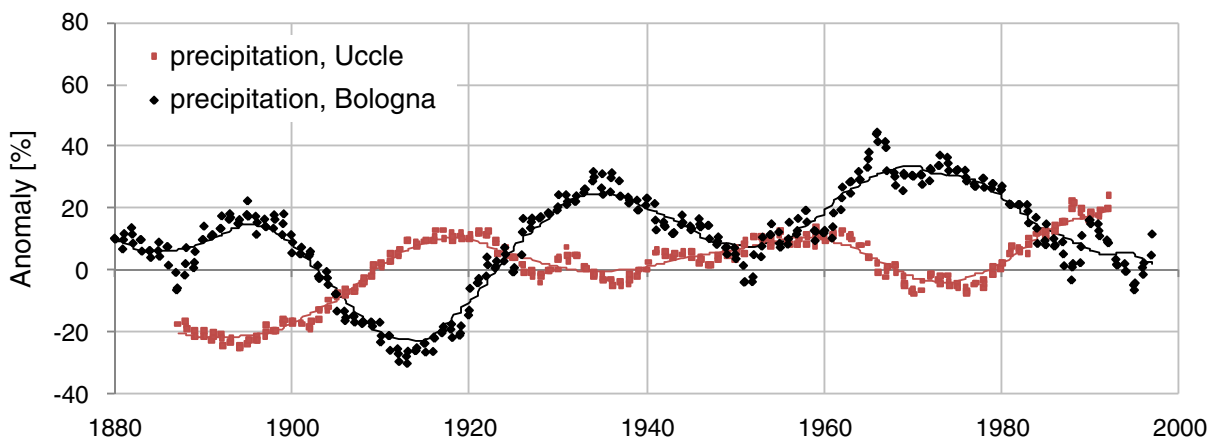

Fig. 6 Anomalies in quantiles of monthly precipitation, anti-correlated between Uccle, in central-western Europe, and Bologna, in southern Europe, for 15-years subperiods and all months in DJF (ECA\&D database) 

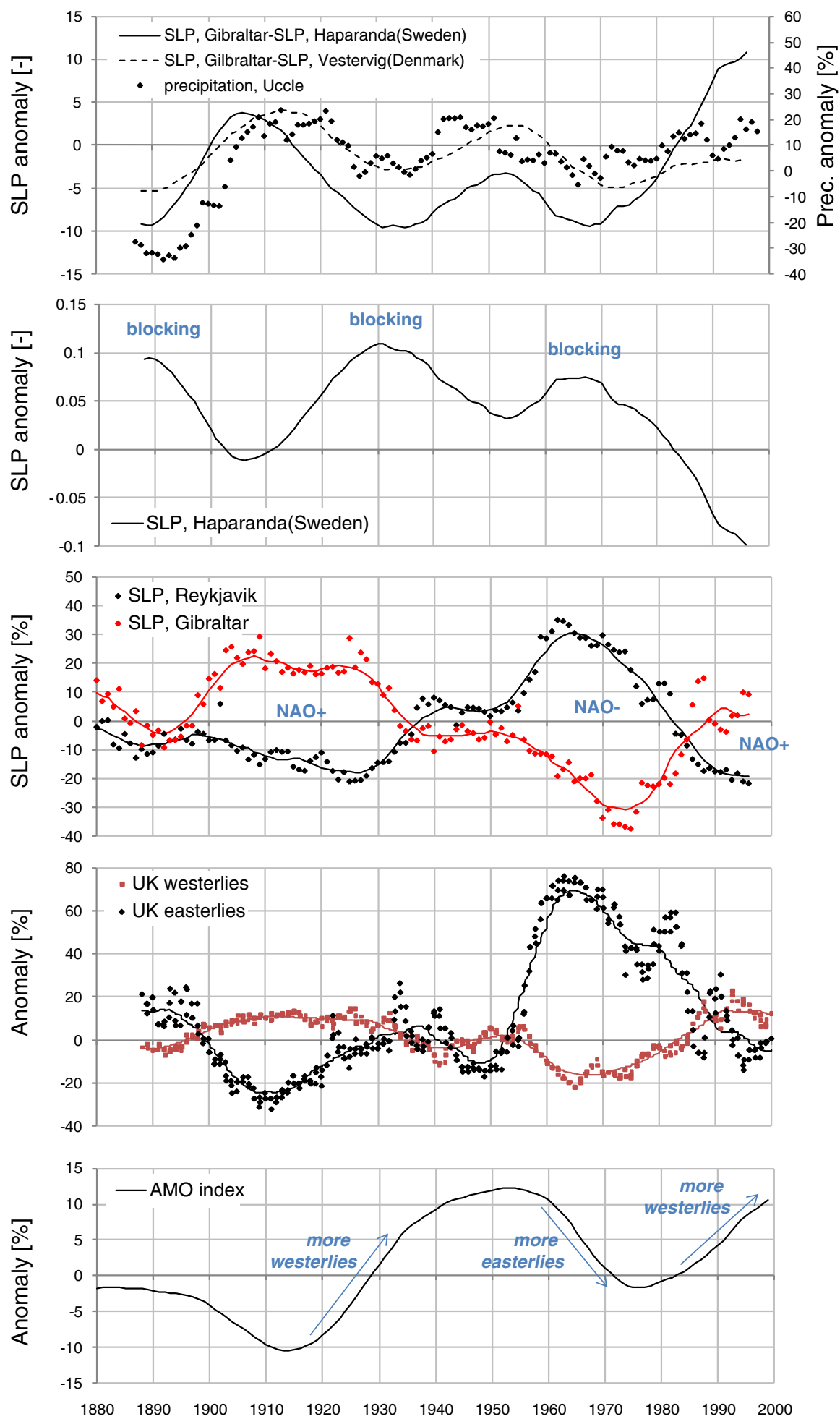
Fig. 7 Comparison of anomalies based on quantiles of the monthly ASO index, which represents the SLP difference between Gibraltar (The Azores) and Haparanda (Sweden), and between Gibraltar and Vestervig (Denmark) (ECA\&D database), with the anomalies in quantiles of monthly precipitation at Uccle (top figure); with the anomalies based on quantiles of monthly SLP at Haparanda (Sweden) (second figure), Reykjavik (Iceland) and Gibraltar (third figure); and with the anomalies based on quantiles of the monthly number of days with westerlies and easterlies in the UK following Lamb's synoptic index (fourth figure); and with the anomalies based on quantiles of the monthly AMO index (bottom figure); for 15-years subperiods and all months in DJF

Oscillation lows and highs of precipitation extremes at Uccle are in those seasons caused by similar multidecadal fluctuations in low SLP above that region (Fig. 8). It is expected that for other regions in Europe the multidecadal oscillations in the occurrence of precipitation extremes can be explained by similar but region specific dependencies with atmospheric circulation and its temporal persistence. It is moreover expected that the spatial dependencies in atmospheric circulation explain the (anti-)correlations of the precipitation oscillations across Europe.

Despite the conclusions drawn based on Fig. 7 that the precipitation oscillations over western Europe have a stronger link with the ASO index than with the NAO index, links with the NAO index are existent. NAO index, which reflects the SLP north-south dipole anomaly in the North Atlantic Ocean, was in positive phases during the precipitation oscillation highs of the 1910s and 1990s. During the 1950-1960s oscillation high, the NAO index was not in a positive phase (it rather went in a negative phase about a decade later), while the ASO index was positive in that period. For the 1910s and 1990s-2000s oscillation highs, both the NAO
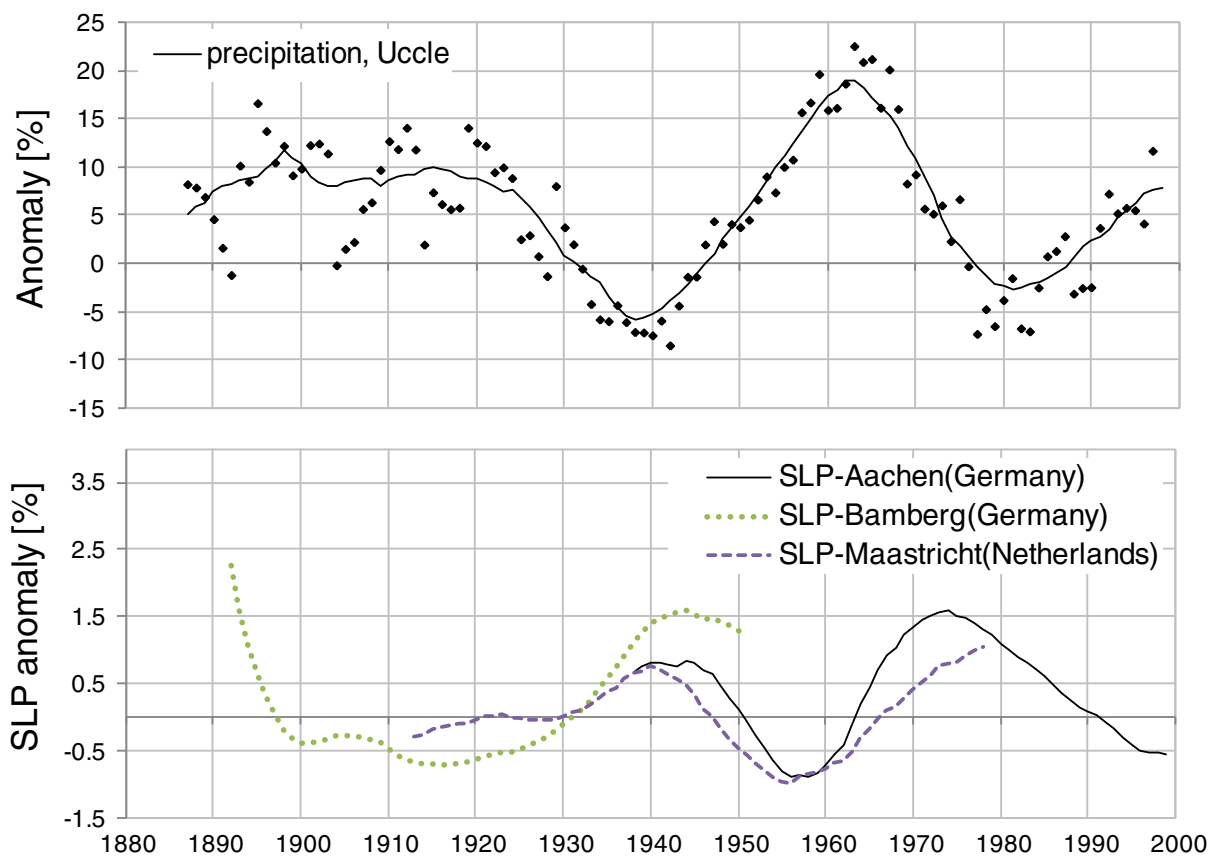

Fig. 8 Comparison of anomalies in quantiles of monthly precipitation at Uccle (top figure), with the anomalies based on the quantiles of monthly SLP at Aachen and Bamberg (Germany) and Maastricht (The Netherlands) (bottom figure), for 15-years subperiods and all months in JJA 
and ASO indices were in positive phase, where for the 1990s-2000s the ASO index was much higher in comparison with the NAO index.

\section{Conclusion}

The temporal clustering of rainfall extremes has long been a blurred phenomenon to researchers concerned with investigating temporal variability of rainfall intensities. Based on a technique for the identification and analysis of changes in extremes, this paper affirms that rainfall extremes in Europe have oscillatory behaviour at multidecadal time scales. Moreover, it is shown that the recent upward trend in these extremes is for central-western Europe partly related to a positive phase of this oscillation.

The analysis started based on a worldwide unique dataset of 108 years of 10-minute rainfall intensities at Uccle (Brussels). We also checked the consistency of the findings with long(er), but less resolute records of daily and monthly precipitation, cloud cover, temperature and river flow in neighbouring regions of northwestern Europe. The past 100 years showed for Brussels and neighbouring regions higher rainfall quantiles for the 1910 s, the 1950-1960s, and more recently during both winter and summer of the past 20 years. These conclusions were found consistent for all time scales varying from $10 \mathrm{~min}$ to the monthly scale. The increase/decrease in rainfall quantiles was due to an increase/decrease in the number of extreme precipitation events and by higher/lower precipitation intensity per event, where the first factor was found most important. The increases were found statistically significant at the $5 \%$ confidence level, and were found to be partly explained by persistence in atmospheric circulation patterns over the North Atlantic during periods of 10 to 15 years.

After calculating multidecadal oscillations in SLP data, we could show that for the winter (DJF) season the multidecadal oscillations in precipitation extremes coincide with anomalous periods for the pressure difference between the Azores and Scandinavia (ASO index), and with the number of days with westerlies/easterlies. This dependence should be explained by SLP/atmospheric circulation/climate links. For summer (JJA), the multidecadal oscillation highs in precipitation extremes coincide for Uccle with periods where cyclonic weather types (low SAP) occur more often.

The multidecadal climate oscillations in western Europe and regions of the North Atlantic (North America and North Africa) (Enfield et al. 2001; Sutton and Hodson 2005) thus appear related to fluctuations in atmospheric circulation patterns, which persist over periods of 10 to 15 years. Research presented in this study shows that these oscillation patterns played a prominent role in explaining some of the general increasing trend in precipitation extremes during the past 20 years. This is the case for the DJF precipitation extremes at Uccle, Belgium, and other stations in central-western Europe such as The Netherlands, Denmark and the south of Norway. Even a decreasing trend (for the next decade) might have been initiated for that region. The research also showed anti-correlations between central-western and southern Europe. It would be worth studying whether these oscillations and correlations can also be found in river flow series. Similar north-south differences as found in this study (Figs. 4 and 5) can be noted in the study by Stahl et al. (2010, 2012) and Hannaford et al. (2012) on recent river flow trends across Europe.

The driving forces of the climate oscillations are unknown to date. They might be the result of complex interactions between the atmosphere, the oceans, the sea ice, etc., with lag times due to the characteristic time scales of these different components, additionally or potentially primarily driven by solar activity. Research to find these key drivers is a key to improve our understanding of climate change, including both variability and trends. 
Acknowledgments The author would like to thank the Laboratoire des Sciences du Climat et de l'Environnement (LSCE), Gif-sur-Yvette, France, more in particular Dr. Pascal Yiou for the support in physically explaining the links with large scale circulation. The research visit to the LSCE was facilitated by a travel grant of the Fund for Scientific Research (FWO)-Flanders. The historical Uccle series were provided by the Royal Meteorological Institute of Belgium. The author also acknowledges the data providers in the ECA\&D project, and the three anonymous reviewers for their detailed review and suggestions.

Open Access This article is distributed under the terms of the Creative Commons Attribution License which permits any use, distribution, and reproduction in any medium, provided the original author(s) and the source are credited.

\section{References}

Ashagrie AG, de Laat PJM, de Wit MJM, Tu M, Uhlenbrook S (2006) Detecting the influence of land use changes on Floods in the Meuse River Basin - the predictive power of a ninety-year rainfall-runoff relation. Hydrol Earth Syst Sci Discuss 3:529-559

Baguis P, Roulin E, Willems P, Ntegeka V (2009) Climate change scenarios for precipitation and potential evapotranspiration over central Belgium. Theor Appl Climatol 99(3-4):273-286

Chow VT, Maidment DR, Mays LW (1988) Applied hydrology. McGraw-Hill, New York

Christensen JH, Christensen OB (2003) Climate modelling: severe summertime flooding in Europe. Nature 421:805-806

Delworth TL, Mann ME (2000) Observed and simulated multidecadal variability in the Northern Hemisphere. Clim Dyn 16:661-676

Demarée GR (2003) Le pluviographe centenaire du plateau d'Uccle: son histoire, ses données et ses applications. La Houille Blanche 4:1-8

Deser C, Blackmon M (1993) Surface climate variations over the North Atlantic ocean during winter: 19001989. J Clim 6:1743-1753

Enfield DB, Mestas-Nunez AM, Trimble PJ (2001) The Atlantic multidecadal oscillation and its relation to rainfall and river flows in the continental U.S. Geophys Res Lett 28:2077-2081

Faure H, Gac J-Y (1981) Will the Sahelian drought ends in 1985? Nature 291:465-478

Fischer H, Mieding BA (2005) 1,000-year ice core record of interannual to multidecadal variations in atmospheric circulation over the North Atlantic. Clim Dyn 25:65-74

Folland CK, Parker DE, Kates FE (1984) Worldwide marine temperature fluctuations 1856-1991. Nature 310:670-673

Gillett NP, Zwiers FW, Weaver AJ, Stott PA (2003) Detection of human influence on sea level pressure. Nature 422:292-294

Goldenberg SB, Landsea CW, Mestas-Nuñez AM, Gray WM (2001) The recent increase in Atlantic hurricane activity: causes and implications. Science 293:474-479

Gregersen IB, Sørup HJD, Madsen H, Rosbjerg D, Mikkelsen PS, Arnbjerg-Nielsen K (2013) Assessing future climatic changes of rainfall extremes at small spatio-temporal scales. Clim Chang. doi:10.1007/s10584012-0669-0

Grosfeld K, Lohmann G, Rimbu N, Fraedrich K, Lunkeit F (2007) Atmospheric multidecadal variations in the North Atlantic realm: proxy data, observations, and atmospheric circulation model studies. Clim Past 3:39-50

Hannaford J, Buys G, Stahl K, Tallaksen LM (2012) The influence of decadal-scale variability on trends in long European streamflow records. Hydrol Earth Syst Sci Discuss 10:1859-1896

Hulme M, Barrow E (1997) Climate of the British Isles: present, past and future. Routledge, London

Hurrell JW (1995) Decadal trends in the North Atlantic Oscillation: regional temperatures and precipitation. Science 269:676-679

IPCC (2007) Climate change 2007: The physical science basis, summary for policymakers, Contribution of Working Group I to the Fourth Assessment Report of the Intergovernmental Panel on Climate Change, IPCC Secretariat, Geneva, Switzerland

IPCC (2012) In: Field CB (ed) Managing the risks of extreme events and disasters to advance climate change adaptation. A special report of working groups I and II of the intergovernmental panel on climate change. Cambridge University Press, Cambridge and New York

Jones PD, Jónsson T, Wheeler D (1997) Extension to the North Atlantic Oscillation using early instrumental pressure observations from Gibraltar and South-West Iceland. Int J Climatol 17:1433-1450 
Jones GS, Tett SFB, Stott PA (2003) Causes of atmospheric temperature change 1960-2000: a combined attribution analysis. Geophys Res Lett 30:1228

Kerr R (2000) A North Atlantic climate peacemaker for the centuries. Science 288:1984-1986

Klein Tank AMG et al (2002) Daily dataset of 20th-century surface air temperature and precipitation series for the European Climate Assessment. Int J Climatol 22:1441-1453

Kundzewicz ZW (ed) (2012) Changes in flood risk in Europe. CRC Press, London

Lamb HH (1972) British Isles Weather types and a register of daily sequence of circulation patterns, 18611971. Geophys. Memoir 116, HMSO, London, UK

Lambert FH, Stott PA, Allen MR, Palmer MA (2004) Detection and attribution of changes in 20th century land precipitation. Geophys Res Lett 31, L10203

Lenderink G, van Ulden A, van den Hurk B, Keller F (2007) A study on combining global and regional climate model results for generating climate scenarios of temperature and precipitation for the Netherlands. Clim Dyn 29(2):157-176

Luterbacher J, Dietrich D, Xoplaki E, Grosjean M, Wanner H (2004) European seasonal and annual temperature variability, trends, and extremes since 1500. Science 303:1499-1503

Mann ME, Park J, Bradley RS (1995) Global interdecadal and century-scale climate oscillations during the past five centuries. Nature 378:266-270

Min S-K, Zhang X, Zwiers FW, Hegerl GC (2011) Human contribution to more-intense precipitation extremes. Nature 470:378-381

Ntegeka V, Willems P (2008) Trends and multidecadal oscillations in rainfall extremes, based on a more than 100 years time series of 10 minutes rainfall intensities at Uccle, Belgium. Water Resour Res 44, W07402

Schlesinger ME, Ramankutty N (1994) An oscillation in the global climate system of periods 65-70 years. Nature 367:723-726

Stahl K, Hisdal H, Hannaford J, Tallaksen LM, van Lanen HAJ, Sauquet E, Demuth S, Fendekova M, Jódar J (2010) Streamflow trends in Europe: evidence from a dataset of near-natural catchments. Hydrol Earth Syst Sci 14:2367-2382

Stahl K, Tallaksen LM, Hannaford J, van Lanen HAJ (2012) Filling the white space on maps of European runoff trends: estimates from a multi-model ensemble. Hydrol Earth Syst Sci 16:2035-2047

Stott PA (2003) Attribution of regional-scale temperature changes to anthropogenic and natural causes. Geophys Res Lett 30:1724

Sutton RT, Hodson DLR (2005) Atlantic Ocean forcing of North American and European summer climate. Science 290:2133-2137

Wentz FJ, Ricciardulli L, Hilburn K, Mears C (2007) How much more rain will global warming bring? Science 317:233-235

Willems P (2000) Compound intensity/duration/frequency-relationships of extreme precipitation for two seasons and two storm types. J Hydrol 233:189-205

Willems P (2013) Revision of urban drainage design rules after assessment of climate change impacts on precipitation extremes at Uccle, Belgium. J Hydrol 496:166-177

Willems P, Vrac M (2011) Statistical precipitation downscaling for small-scale hydrological impact investigations of climate change. J Hydrol 402:193-205

Willems P, Olsson J, Arnbjerg-Nielsen K, Beecham S, Pathirana A, Bülow Gregersen I, Madsen H, Nguyen VT-V (2012) Practices and impacts of climate change on rainfall extremes and urban drainage. IWA Publishing, ISBN 9781780401256

Yiou P, Masson-Delmotte V (2005) Trends in sub-annual climate variability since the Little Ice Age in western Europe. C R Geosci 337:1001-1012

Yiou P, Nogaj M (2004) Extreme climatic events and weather regimes over the North Atlantic: when and where? Geophys Res Lett 31, L07202

Zhang X, Zwiers FW, Hegerl GC, Lambert FH, Gillett NP, Solomon S, Stott PA, Nozawa T (2007) Detection of human influences on twentieth-century precipitation trends. Nature 448:461-465 